\title{
Business Ecosystem, a Secured Strategy to Gain Competitive Advantage According to SMOCS Model
}

\author{
Narges Alizadeh ${ }^{1}$, Hanieh Effati Dariani ${ }^{2}$, Ali Smida ${ }^{3}$ \\ ${ }^{1}$ UniRouen, Uni Havre, University of Havre, 76600 le Havre, France \\ ${ }^{2}$ School of Management, Science and Research branch, Islamic Azad University, Tehran, Iran \\ ${ }^{3}$ School of Management Science CEPN, CNRS UMR 7234, Iran \& Director of the MOSS Master University of \\ Paris 13 - Sorbonne University Paris Cité, France \\ Correspondence: Narges Alizadeh, UniRouen,Uni Havre, University of Havre, 76600 le Havre, France.
}

Received: August 1, 2016

doi:10.5539/ibr.v10n8p72

\author{
Accepted: July 3, $2017 \quad$ Online Published: July 11, 2017 \\ URL: https://doi.org/10.5539/ibr.v10n8p72
}

\begin{abstract}
Attitude to the organizations has been changed over the time. Nowadays by increasing changes in business environments, borders between industries have almost been removed. According to James Moore (1993), organizational activities space is now an ecosystem one in which different businesses from different industries have mutual interactions as well as their survivals extensively depend on each other. These concepts are thoroughly propounded in business ecosystem approach.

This paper reviewed different types of making strategic decision by using SMOCS Model was presented by Smida 1995 and showed which consequences and results shall be gained in each type for business ecosystem. It also showed scientific and applicable methods of making strategic decision according to SMOCS Model. So each business ecosystem may choose one of strategic decision making types as per situation and its expectation from the results. The method which applied in this research also authorized us to study a concurrent and simultaneous decision making in three main and important variables (resources, objectives and environmental conditions).Results of this research may help managers to make strategic decision in critical situations and also propose effective and useful offers to make decision. It raises knowledge and awareness level in making decision.
\end{abstract}

Keywords: business ecosystem, making strategic decision, SMOCS Model

\section{Introduction}

It is inevitable and necessity that changes are happened in business world. Some of these changes are happened gradually and for improving business activities but the others are fundamental and associate with fundamental variations in business in such a manner that "revolution" phrase (like Industrial Revolution) is used for total of these changes. Revolution phrase shows not just changes in modus operandi but variations in life style, thinking ways and perception about the world. (Hearn, G., \& Pace, C., 2006)

Nowadays despite of increasing changes and evolutions in business world and information revolution, it is necessary to make changes in modus operandi, life, thinking and perception about the world. The basics of all these changes depend on mental changes and these mental changes need an open and dynamic mind. Conceptual basics of business ecosystem approach is just one of those methods help to changes happen in people minds to could better understand new situation in business world and prepare for that.

As mentioned before competition is now between business ecosystems not companies and whatever causes industrial evolution is rivalry in business ecosystem level. Managers should not ignore new ecosystems or competitions between current ecosystems as well as they should know conceptual basics of this approach and use them before exploiting business ecosystems. (J. Knowledge, 2008)

In business ecosystem, organizations play different roles and by virtue of members' roles, importance of these conceptual basics are partly changed. On the other hand, it is possible that an organization becomes a member of several ecosystems simultaneously and play a different role in each one but for being success in current age which is innovation economic era, these conceptual basics are necessary. According to Peter Senge (2008) it is 
necessary (Hearn, G., Pace, C., 2006 \& Holland, J. H., 1992) for the organization to have cooperation inside its borders to create sustained future as well as basics of business ecosystem approach focuses on inter-organizational interactions.

The aim of this paper is explicating conceptual basics of business ecosystem approach which are stated on the basis of revisal studying and analyzing related subjects to business concepts and changes in business world in recent decades. Overall it shall be changes in people minds by accepting these basics which make them see business issues by an open and dynamic mind and seek accepting new variations and even making them. In fact, this approach discusses a new method in looking at business which is of course applicable in more extensive dimensions such as individual and social life expansion of people.

As stated before, these conceptual basics focus on inter-organizational interactions and by effecting on robustness and niche creation for organization and other members of ecosystem shall finally result in organization productivity. Function of any ecosystems' member also depends on management and its' capability to exploit opportunities which are available inside the ecosystem.

Generally organizational activities are now happened in eco-systematic space, competition is between business ecosystems not organizations and it is necessary to consider changes in business environments to be success in this space, to make changes in minds to be prepared for these variations, even sometimes move beyond and make these changes. Business ecosystem approach is one of the theories which are proper for being active in current age because of changes happened in recent decades, so understanding these conceptual basics are necessary for being success in business which is discussed in this paper.

The scope of this paper is to propose a metrology for analyzing and modeling the business ecosystem according to SMOCS model to illustration its application in strategy decision - making in business ecosystem .The aim of this study is to identify affecting factors in strategic decision - making in a business ecosystem is based on model SMOCS in this study we will try to show the different aspect strategy decision -making in one of the cooperation between companies in business - ecosystem, also we intend to challenge the theory business ecosystem in strategy decision -making . in this study was introduced various models of cooperation in a business ecosystem according to model SMOCS, which were not present and also identified practical approaches in domain different cooperation in business ecosystem.

\section{The Origins of the Concept "Business Ecosystem"}

The concept first appeared in Moore's May/June 1993 Harvard Business Review article, titled "Predators and Prey: A New Ecology of Competition", and won the McKinsey Award for article of the year (Mckinsey Award Winners, 2001)

Moore defined "business ecosystem" as: "An economic community supported by a foundation of interacting organizations and individuals - the organisms of the business world. The economic community produces goods and services of value to customers, who are themselves members of the ecosystem. The member organisms also include suppliers, lead producers, competitors, and other stakeholders. Over time, they co - evolve their capabilities and roles, and tend to align themselves with the directions set by one or more central companies. Those companies holding leadership roles may change over time, but the function of ecosystem leader is valued by the community because it enables members to move toward shared visions to align their investments, and to find mutually supportive roles. (J. Knowledge, 2008)

Moore used several ecological metaphors, suggesting that the firm is embedded in a (business) environment, that it needs to co-evolve with other companies, and that "the particular niche a business occupies is challenged by newly arriving species." (J. Knowledge ,2008) This meant that companies need to become proactive in developing mutually beneficial ("symbiotic") relationships with customers, suppliers, and even competitors.

Biological ecosystems: Some environmentalists have used "business ecosystems" as a way to talk about environmental issues as they relate to business rather than as a metaphor to describe the increasing complexity of relationships among companies. According to Townsend, business ecology is the study of the reciprocal relationship between business and organisms and their environments. The goal of this "business ecology" is sustainability through the complete ecological synchronization and integration of a business with the sites that it inhabits, uses, and affects. (Townsend, Amy K, 2009)

Other environmentalists believe that the ecosystem metaphor is just a way for business to appear 'Green'. According to author Alan Marshall, the metaphor is used to make out that somehow business operates using natural principles which should be left to run without interference by governments. 


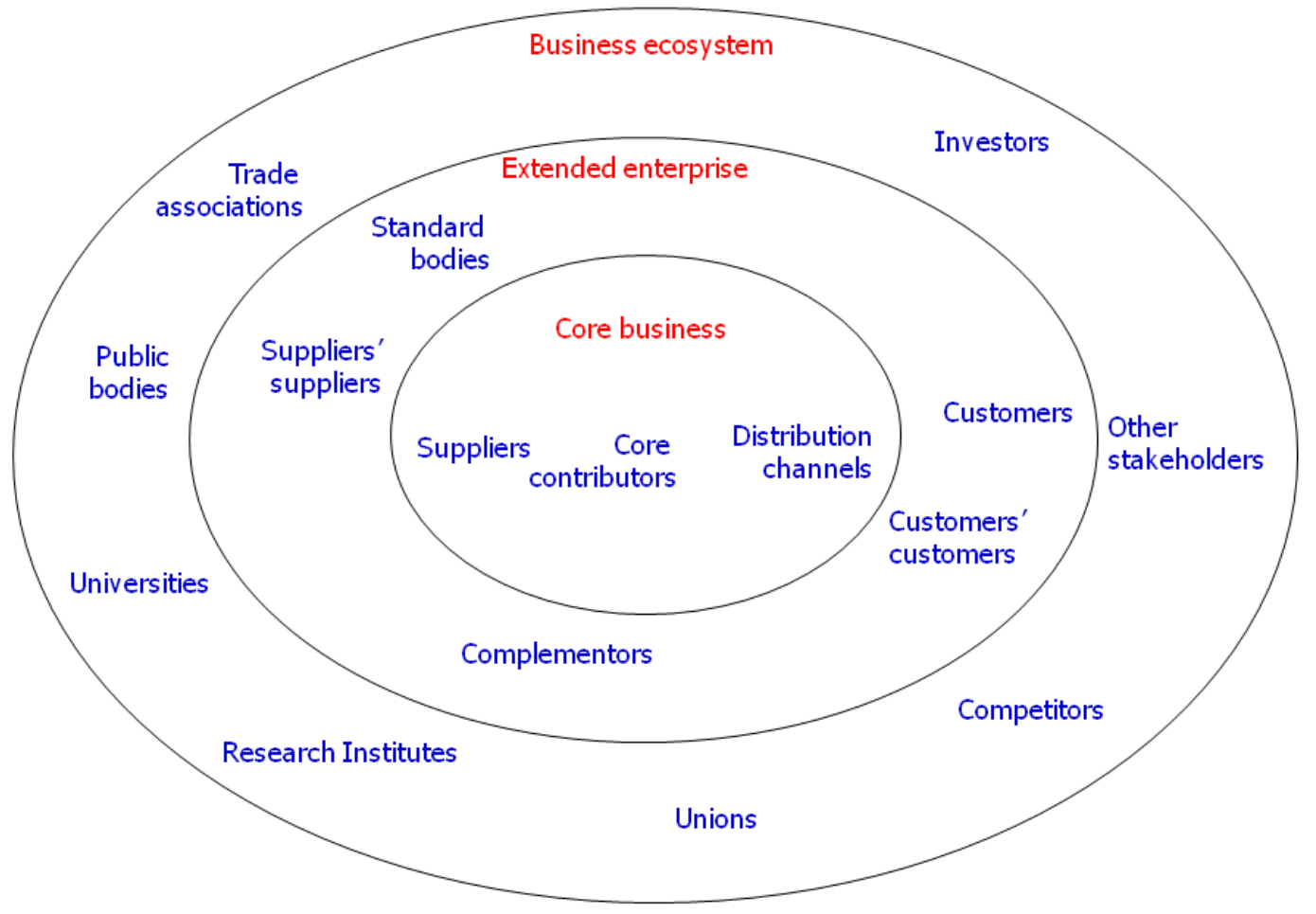

Figure 1. The layers of a business ecosystem adapted from Moore (1993)

\subsection{Business Ecosystem Concept}

Ecosystem is one of applied concepts in environmental field. An ecosystem is a community of living organisms in conjunction with around environment. Ecosystems are not just a body of species but combined from living, nonliving components and natural forces which are in mutual interactions and continuously change. Behavior of a living body effects on another one and also on ecosystem environment; ecosystem destiny and survival depends on behavior of its all members. Organizational behavior is similar to organisms of an ecosystem by increasing interconnection of organizations and being more complex of businesses interactions on one hand and increasing velocity of environmental changes in business world in recent decades on the other hand.

Business ecosystem metaphor has been prolonged for the first time by James Moore (1993). According to this metaphor the space of organizational activities is now a business ecosystem; an ecosystem which is combined from members such as customers, suppliers, pioneer producers, stakeholders, commercial communities, trade unions, governmental and semi-governmental institutes and other beneficiaries. There are mutual and complex relations between these members and their success and survival depend on each other. (Anggraeni, E., Den Hartigh, E., Zegveld, M., 2007 \& Barabasi, A. L., 2002 \& J. Knowledge ,2008)

Business ecosystem is a de veloped system from organizations which protect each other.( Den Hartigh, E., Tol, M., Visscher, W., 2006) From ecosystem point of view, it is believed that any member effects on the whole business ecosystem destiny. On the other word, entering and exiting of any member shall touch the operation of other members. For example when the number of a network customers decreases, value of the network shall be deducted for suppliers and other customers. Also if a new supplier of a supplement product enters the network, the network value shall increase for all members. (Den Hartigh, E., Tol, M., 2008 \& Franco, F. L., 2011)

\subsection{Conceptual Basics of Business Ecosystem Approach}

Whereas business world is continuously changed, organizational management shall also seek modern methods for being successful in business competitions. Applying these methods shall result in changes in the organization such as changes in technological infrastructures, structural variations, new trainings for stuff, etc. but some of these items need more than organizational variations. Some of these sights need changing in mentality and mental structures. By rapid changes in business world in recent decades, the basics of contests and business have been varied. It needs an open and dynamic mind to realize these changes, to could understand the situations and adopt a proper approach in these conditions to be success. As it was mentioned one of the discussed theories in recent decades is business ecosystem approach. Employing this concept associates with changes in business 
which is discussed here as conceptual basics of business ecosystem approach.

\subsection{Business Ecosystem Function Standards}

If business ecosystem shall be known as business activities space, some standards should be given to measure its function. As this concept was taken from biological sciences, its function standards have been also stated by comparing national ecosystems and business. Before discussing about these standards it should be mentioned that these are applied as a whole for both members of business ecosystem and ecosystem itself. (Glenn, J. C., 1994) Ecosystem function standards are also named health standards. Health of any members shows its management ability and competences in exploiting opportunities which are opened inside the ecosystem. (Moore, J. F., 1996)

Iansiti and Levien (2004) suggested ecosystem function standards or ecosystem health standards. According to them, there are three critical measures of health for business ecosystem: Productivity, Robustness and Creating opportunities. (Moore, J. F., 1993)

\subsection{Productivity}

Productivity is the success key of any business.( Anggraeni E, Den Hartigh E, Zegveld M,2007) Modern competition depends on productivity more than accessing inputs or size of a company. Productivity depends on how companies are in competitions with each other, not to their activities field. Companies could be productive in any industry if use advanced methods and technologies and offer unique productions and services. (Townsend, A. K, 2006)

Ecosystem members should profit their relationships in ecosystem. Ecosystem ability to convert inputs to outputs is called productivity. In fact, productivity critical measures should embrace an ecosystem's effectiveness in converting innovation raw materials to new productions and functions and by less expense. (Moore, J. F., 1993)

\subsection{Robustness}

Robustness is a concept which shows the capability of systems to be survived against sudden changes in their environments. (Anggraeni, E., Den Hartigh, E., Zegveld, M., 2007) Robustness in natural ecosystems means survival capabilities against demolition of threats from inside and/or outside shocks. In business world, robustness means gaining competitive advantage from many resources and capable to converting them as environmental changes are happened. (Anggraeni, E., Den Hartigh, E., Zegveld, M., 2007).

Robustness in organizational systems (a set of organizations) comes from diversity, abundance and ability to being consistent: if organizational systems have enough diversity, in case of ceasing to exist of some members, other ones could be replaced; if organizational systems have enough abundance, capabilities of extinct members could be found in existing members and finally if the organizational systems able to be consistent, could rapidly change and promote those capabilities which have vanished. (Anggraeni, E., Den Hartigh, E., Zegveld, M., 2007).

\subsection{Creating Opportunities}

One of the specifications of business ecosystem is capability to create opportunities for new companies. (Anggraeni, E., Den Hartigh, E., Zegveld, M., 2007) Cornerstone of a business ecosystem is essential core technology (Den Hartigh, E., Van Asseldonk, T., 2004 \& Moore, J. F., 1996) which is applied by different organizations from different industries and organizations establish their activities on its basis. This concept indicates opportunity creation in ecosystem. On the other hand, de veloping activities and also participation of organization in forming environmental changes prepare new opportunities for organization and also other members of ecosystem. (Anggraeni, E., Den Hartigh, E., Zegveld, M., 2007)

\subsection{Conceptual Basics of Business Ecosystem Approach and Business Ecosystem Function Standards}

As mentioned before, business ecosystem approach has been emerged as a result of environmental changes. To adopt this approach it needs mental changes to consider business space through a new sight and conceptual basics of this approach indicate these mental changes. Besides, critical measures of being active in this space are productivity, robustness and niche creation. It shall be more clarified the necessity and importance of this approach by realizing the relationship between conceptual basics and business ecosystem function standards which is explained in this part.

At one time companies were creating value by inside activities and their products and services for customers. Nowadays the resource for creating economical value and roots of dominant operation of company is located inside the structure of company's relationships and eco-systematical approach indicates business network in the best manner; organizations are successful which could better exploit from their relationships with other members of the network. 
One of the specifications of eco-systematic approach is that its' activities focus on creating value not just the product itself. Standards of being active in this space are productivity, robustness and niche creation. At the first eco-systematic activities may accomplish to increase robustness and niche creation but finally shall end to increasing productivity, because ecosystem members should profit their relationships with other members.( Den Hartigh E, Tol M,2008) On the other word, eco-systematic approach includes whole effective factors on value production and creation without direct effect on productivity.( Peltoniemi, M. ,2005) For example:

- It is increasing the possibility of exploiting opportunities and opportunity creation by de veloping business extent;

- Developing business networks increases protection against environmental threats and shocks and shall result in robustness increment;

- Improvement of business networks function shall increase competitive in network level and ecosystem as competitive units as well as result in network, ecosystem and finally organization productivity; and

- Making environmental changes shall increase possibility of creating better future for the organization. Natural, social, political, scientific and technological forces specify the future to much extent. Though by increasing human interferences this is our choices which form the future. It is increasing to exploit opportunities and opportunity creation by making environmental changes.

\section{Research Modeling}

This research tries to introduce a special scientific method for making strategic decision associate with several important standards (resources, environmental conditions and objectives). There are several scientific methods which could help companies in making strategic decision. But in this research we chose SMOCS model (tools strategy, objectives and restriction scenario) (Shapiro C, Hal V, 1998) which shall permit to study decision making concurrently and integrated in three areas (objectives, resources and environmental conditions). This method is the first coherent one to make strategic decision with three variables (objectives, resources and environmental conditions) (Shapiro C, Hal V, 1998). SMOCS model has been inspired from Venn diagram theory and based on community theory. This model helps managers to make decision in uncertainty situations.SMOCS Model shall be applied as a scientific and applicable method to make strategic decisions in future. (Smida, A, 1995)

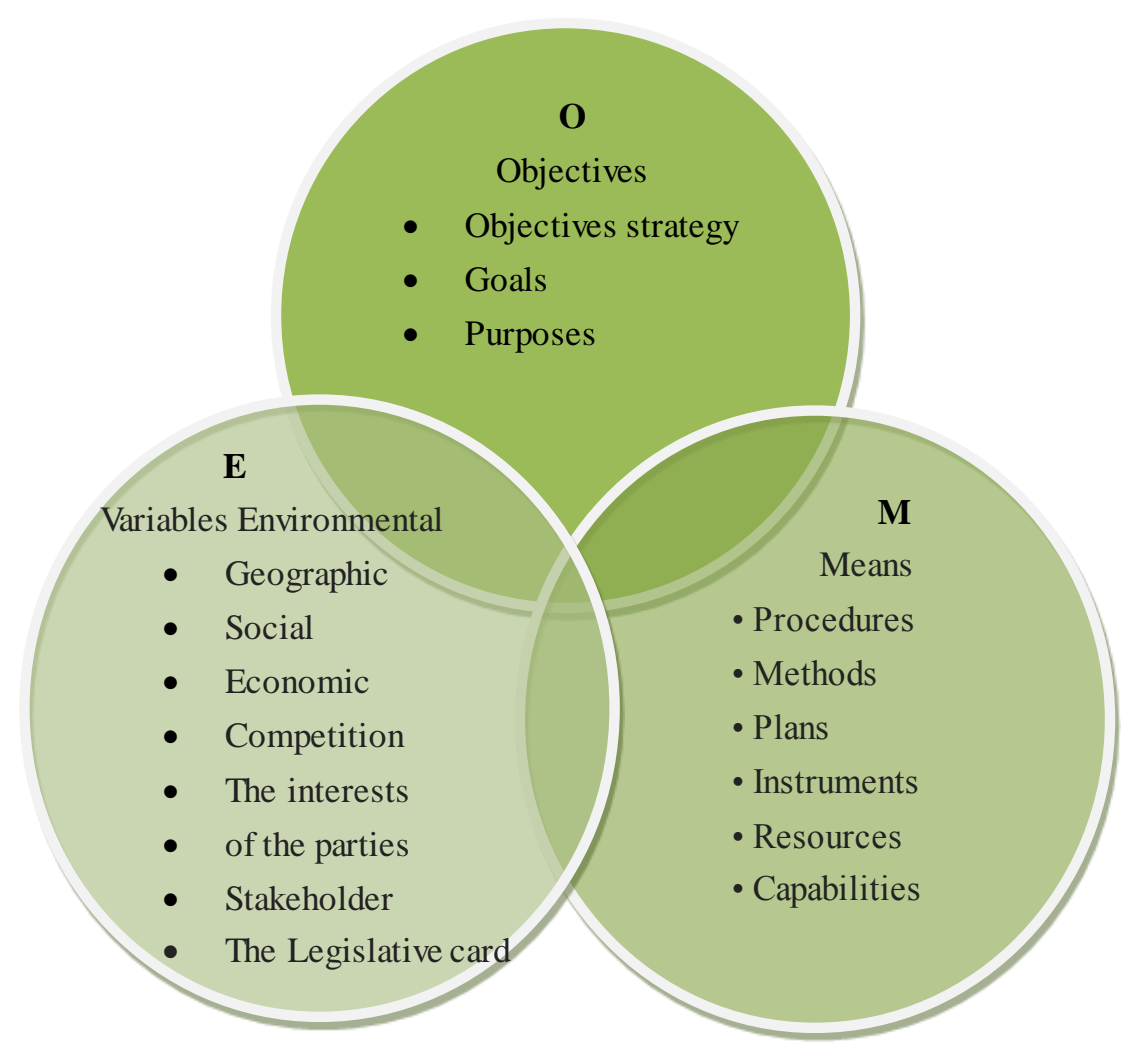

Figure 2. SMOCS Model (objectives, resources and environmental conditions (Shapiro C, Hal V, 1998)) 
$S$ M: indicant of organizational resources.

S O: indicant of organizational objectives and vision of the organization's strategies.

$\mathrm{S}$ E: variables of environmental conditions which effect on organization.

According to these 3 important variables in making strategic decision, the model shows different solutions. Any organization may achieve acceptable results in making strategic decision by virtue of conditions and expectations.

Table 1. Determining factors in cooperation Business Ecosystems based on model SMOCS (Smida, A., 2003)

\begin{tabular}{cl}
\hline Category & Determining Factors of cooperation \\
\hline Environmental Conditions & Competitive Conditions \\
& Environmental institutional \\
The dynamics of change in the environment socio - cultural & (the customer's request ...) \\
& The dynamics of change in the environment technology \\
& Innovation technologique \\
& high costs and complexity of technological systems \\
& Convergence between technologies and standard \\
\hline Resource & $\begin{array}{l}\text { Improved Branding } \\
\text { The heterogeneity of resources between firms } \\
\text { Interdependence in terms of resource }\end{array}$ \\
\hline Objectives & $\begin{array}{l}\text { Achieving economies of scale } \\
\text { Pooling strengths sufficient for the creation of a competitive } \\
\text { advantage } \\
\text { Penetration of new markets }\end{array}$ \\
\hline
\end{tabular}

Based on SMOCS Model how can we make strategic decision in a business ecosystem?

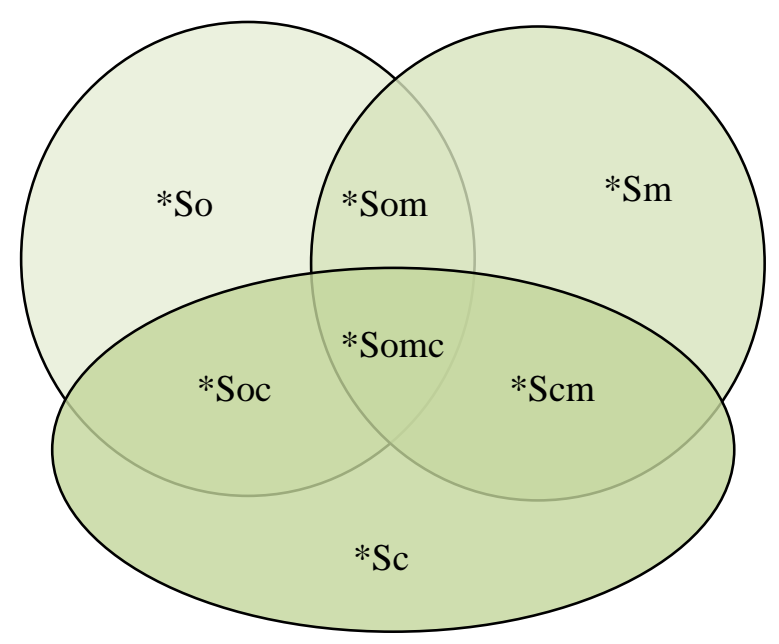

Figure 3. Categorizes of cooperation between 3 dimensions according to SMOCS Model

1- This area in business ecosystem means that decisions are made just based on community and cooperation and organizational goals. In business ecosystem companies and institutes cooperate each other according to common projects which related to promote organizational goals. By cooperation strategy, they could benefit capabilities of each other to gain competitive advantage and make them complete to could expose their potential capabilities to compete other business ecosystems.

2- This area of making decision in business ecosystem means that companies and organizations shall cooperate each other by bolding strengths and paling weaknesses. It means organizations and companies shall recognize each other's strengths and weaknesses in business ecosystem and try to bold opportunities and create them. They also attempt to cover other side's weaknesses and minimize environmental threats. This making decision region is about gaining better opportunities, establishing strengths, covering weaknesses and decreasing environmental threats.

3- This area of decision making in business ecosystem shall be carried out according to cooperation of organizational resources between companies and institutes. It means to make a competitive advantage, 
companies decide to cooperate each other in financial and non-financial resources to make themselves strong in this area and benefit common capabilities to gain optimized situation.

\section{Conclusion}

This paper has a goal of challenging methods about strategic decision making in a business ecosystem according to SMOCS Model.

As mentioned before, according to definition of business ecosystem companies and institutes cooperate each other to achieve competitive advantage. In a business ecosystem, it is sometimes needed to make important strategic decisions and to gain competitive advantage. Companies and institutes should decide in which areas (resources, objectives and environmental conditions) they want cooperate each other.

This paper reviewed different types of making strategic decision by using SMOCS Model and showed which consequences and results shall be gained in each type for business ecosystem. It also showed scientific and applicable methods of making strategic decision according to SMOCS Model.

So each business ecosystem may choose one of strategic decision making types as per situation and its expectation from the results.

The method which applied in this research also authorized us to study a concurrent and simultaneous decision making in three main and important variables (resources, objectives and environmental conditions).

Results of this research may help managers to make strategic decision in critical situations and also propose effective and useful offers to make decision. It raises knowledge and awareness level in making decision.

\section{References}

Anggraeni, E., Den, H. E., \& Zegveld, M. (2007). Business ecosystem as a perspective for studying the relations between firms and their business Networks. ECCON.

Barabasi, A. L. (2002). The New Science of Networks. Cambridge, MA, Perseus Publishing.

Book Excerpt Cited in Reflections. (2008). J. Knowledge. Learning. Change, 9(2), 20-33.

Davenport, T. H., Leibold, M., \& Voelpel, S. (2006). Strategy, 444.

Den Hartigh, E., \& Tol, M. (2008). Business Ecosystem, Encyclopedia of Networked and Virtual Organizations, 1, 106-111.

Den Hartigh, E., \& Van Asseldonk, T. (2004). A Research Framework for Investigating the Relation between Network Structure. ECCON 2004 Annual Meeting: Co-Jumping on a Trampoline, The Netherlands.

Den Hartigh, E., Tol, M., \& Visscher, W. (2006). The health measurement of a business ecosystem. Paper presented for the ECCON 2006 Annual meeting, Organisations as Chaordic Panarchies, 20-21 October.

Franco, F. L. (2011). Canen AG, Pizzolato ND, Strategic Alliances: Tools for Constructing the Future. Business Strategy Series, 12(2), 84-97. https://doi.org/10.1108/17515631111114886

Glenn, J. C. (1994). Scenarios Futures Research Methodology,2, AC/UNU, Millennium Project.

Hearn, G. P. C. (2006). Value-creating ecologies: Understanding next generation business systems. Foresight, 8(1), 55-65. https://doi.org/10.1108/14636680610647147

Holland, J. H. (1992). Adaptation in Natural and Artificial Systems. The University of Michigan.

Iansiti, M., \& Levien, R. (2004). The keystone advantage: What the new dynamics of business ecosystems mean for strategy, innovation, and sustainability, Boston, MA: Harvard Business School Press, ISBN 1591393078.

Iansiti, M., Levien, R., \& Keystones, D. (2004). Framing Operating and Technology Strategy in a Business Ecosystem.

Moore, J. F. (1993). ANew Ecology of Competition. Harvard Business Review, 71(3), 75-83.

Moore, J. F. (1996). The Death of Competition: Leadership \& Strategy in the Age of Business Ecosystems. Published by John Wiely \& Sons Ltd, England, 297.

Moore, J. F. (1998). The rise of a new corporate form. Washington Quarterly, 21(1), 167-181. https://doi.org/10.1080/01636609809550301

Peltoniemi, M. (2005a). Business ecosystem: A conceptual model of an organization population from the perspectives of complexity and evolution, Tampere, Finland: e-BRC Research Reports, 18, ISBN 
9521513403.

Porter, M. E. (1998).Clusters and the new economics of competition. Harvard Business Review, 76(6), 77-90.

Senge, P., Smith, B., Kruschwitz, N., Laur, J., \& Schley, S. (2008). How Individuals and Organizations Are Working Together to Create a Sustainable World. Doubleday.

Shapiro, C., \& Hal, V. (1998). Information rules. Cambridge.MA: Harvard Business School Press. Approaches and Tools for Dynamic Innovation Capabilities. Publicis KommunikationsAgentur Gumby, GWA, Erlangen.

Smida, A. (1995). Ingredients foresight and strategy levers .in A. Christmas, P. Very and Mr. Wissler (ed.), Strategic Management Perspectives, Volume III, Economic, 455-483.

Smida, A. (2003). Decisions in a universe of constraints: (dir.) Pre-activated approaches, reactive and proactive "in Cadet B., C. and A. Grenier smida, decisions under stress, Caen, Caen University Press, 363-377.

Smida, A., \& Gomez-Mejia, A. (2010) Stress of company, Effort of conceptualization and technology. Management and Avenir, 35,130-148.

Townsend, A. K. (2006). A Five-Part Model for Creating an Environmentally Responsible Company. Atglen, PA: Schiffer Publishing.ISBN 13: 9780764325038 Hardcover.

Townsend, A. K. (2009). Why Most Green Business Practices Don't Work and What to Do about It. Atglen, PA: Schiffer Publishing.

\section{Copyrights}

Copyright for this article is retained by the author(s), with first publication rights granted to the journal.

This is an open-access article distributed under the terms and conditions of the Creative Commons Attribution license (http://creativecommons.org/licenses/by/4.0/). 